\title{
Randomized Controlled Clinical Trial Comparing Trans- urethral Eneucleation and Resection of Prostate and Trans-urethral Resection of Prostate in the Management of Benign Prostatic Hyperplasia
}

\author{
Hasan $\mathrm{MM}^{\mathrm{a}}$, Afroze $\mathrm{SR}^{\mathrm{b}}$, Rahim $\mathrm{MA}^{\mathrm{c}}$, Salam MA ${ }^{\mathrm{d}}$
}

\begin{abstract}
Background: Transurethral resection of prostate (TURP) is the predominant surgical procedure for benign prostatic hypertension (BPH) but is not devoid of complications like capsular perforation, drop in Hb\%, drop in $\mathrm{Na}^{+}$, residual adenoma; hence endeavors are evolving to combat such complications. A newer technique transurethral enucleation and resection of prostate (TUERP) has been devised to solve these problems. This study was designed to compare the safety and the efficacy of newer technique, TUERP with widely practiced TURP.

Methods: This randomized controlled trial was done at BSMMU, after getting ethical approval from the ethical review committee of the institute, from January to October, 2009. A total of 60 BPH patients were purposively enrolled in this study, after obtaining informed written consent and they were randomized as control, Group A (30 patients, underwent TURP) and experimental group, Group B (30 patients, underwent TEURP).

Results: The mean preoperative Hb\% level of Group A was $15.1 \mathrm{gm} \%(S D \pm 0.5)$ and perioperative $\mathrm{Hb} \%$ level was $13.04 \mathrm{gm} \%(S D \pm 6.06)$. There was significant difference $(P<0.05)$. The mean preoperative $\mathrm{Hb} \%$ of Group B was $15.2 \mathrm{gm} \%(\mathrm{SD} \pm 0.5)$ and perioperative $\mathrm{Hb} \%$ was $15.2 \mathrm{gm} \%(\mathrm{SD} \pm 0.48)$. There was no difference $(P>0.05)$. The mean preoperative $\mathrm{Na}^{+}$of Group $A$ was $140 \mathrm{mmol} / \mathrm{l}(\mathrm{SD} \pm 4.1)$ and perioperative $\mathrm{Na}+$ was 126 mmol/l $(S D \pm 6.8)$. There was significant difference $(P<0.01)$. The mean preoperative Na+ of Group $B$ was $136 \mathrm{mmol} / \mathrm{l}(S D \pm 4)$ and perioperative $\mathrm{Na}+$ was $136 \mathrm{mmol} / \mathrm{l}(S D \pm 2.70)$. There was no difference $(P>0.05)$.

Conclusion: TUERP eliminates drop in $\mathrm{Hb} \%$ and $\mathrm{Na}^{+}$which are usual consequences following TURP. Thus TUERP can be advocated in the treatment of BPH as it also allows completeresection down to surgical capsule.
\end{abstract}

Key wards: TUERP, TURP, $\mathrm{Na}^{+}$drop, $\mathrm{Hb} \%$ drop

(BIRDEM Med J 2017; 7(3): 216-220)

\section{Author Information}

a. Dr. Md. Mehedi Hasan, Assistant Professor, Urology, Kurmitola General Hospital, Dhaka, Bangladesh.

b. Dr. Samira Rahat Afroze, Registrar, Internal Medicine, BIRDEM General Hospital, Dhaka, Bangladesh.

c. Dr. Muhammad Abdur Rahim, Assistant Professor, Nephrology, BIRDEM General Hospital, Dhaka, Bangladesh.

d. Dr. Muhammad Abdus Salam, Professor of Urology and Chairman, Urology and Transplantation Foundation of Bangladesh.

Address of correspondence: Dr. Md. Mehedi Hasan, Assistant Professor, Urology, Kurmitola General Hospital, Dhaka, Bangladesh. Email: mehediuro72@yahoo.com

Received: December 15, 2016
Accepted: July 31, 2017

\section{Introduction}

Benign prostatic hyperplasia $(\mathrm{BPH})$ is one of the most common disease process involved in ageing male. Histological prevalence ranges from $50 \%$ in men aged 51 to 60 years to $90 \%$ in men older than 80 years. ${ }^{1} \mathrm{BPH}$ has a substantial impact on quality of life. Approximately $50 \%$ of all men will develop lower urinary tract symptoms (LUTS) at some points in their lifetime. ${ }^{2}$

Transurethral resection of prostate (TURP) is the predominant surgical procedure for the treatment of $\mathrm{BPH}$. Although a generally safe and efficient method, TURP is associated with some perioperative morbidity, mainly as the result of intraoperative or postoperative bleeding, 
capsule perforation or transurethral resection (TUR) syndrome. ${ }^{3}$ Therefore in the last two decades various alternatives e.g. Holmium Laser Enucleation of Prostate, electrovaporization, needle ablation, high intensity focused ultrasound and microwave thermotherapy were introduced with the aim of reducing morbidity. ${ }^{4-9}$

A newer endoscopic method, transurethral enucleation and resection of the prostate (TUERP), has been devised to solve these problems. In this study we have evaluated the clinical outcome of TUERP and TURP for BPH.

\section{Methods}

This randomized controlled clinical trial was carried out in the Department of Urology, Bangabandhu Sheikh Mujib Medical University (BSMMU), Dhaka from January to October 2009. One hundred and thirty four patients were admitted with prostatic diseases during this period. Among them 60 patients with BPH, who had indication for surgery, were purposively enrolled for the study according to selection criteria and they were randomized into control (30) and experimental (30) groups. First patient was selected for TURP by lottery method followed by TUERP for the second patient and alternately both the procedures were performed.

Patients with BPH having lower urinary tract symptoms (LUTS), International Prostate Symptom Score (IPSS) $>20$, Quality of Life (QOL) $>3$, rectal examination findings suggestive of $\mathrm{BPH}, 30$ to 50 gmprostate volume measured by trans-rectal ultra sound (TRUS) with definite indication for surgery were included in study. Patients with cancer prostate and BPH with significant renal insufficiency, bladder pathology, urethral stricture, urinary tract infection (UTI), diabetes mellitus and hypertension were excluded from the study.

IPSS, QOL score, Q max, post void residue (PVR), prostate volume, pre and postoperative haemoglobin (g/ dl) and pre and postoperative sodium concentration $(\mathrm{meq} / \mathrm{l})$ were the outcome variables.

Approval from the ethical committee of BSMMU was taken. All patients were given an explanation of the study and informed written consents were taken. They were also explained about the safety of the procedure; possible complications and that they had every freedom to quit themselves from the study at any time.

In TUERP, the distal margins of the lateral lobes were marked at the 3 and 9 o'clock positions with the electric loop. This was confirmed accurately by moving the sheath back and forth slowly between the membranous urethra and the verumontanum. By doing so, the adenoma and the ring of the external sphincter could be observed. Then a circular incision of the urethra was made along the previous marking. The incision was approximately 3 to $4 \mathrm{~mm}$ deep and in an anterior oblique direction, since the external sphincter wrap around the urethra obliquely. Circular partial resection of the adenoma with the loop then was performed, leaving unresected adenoma of 0.5 to $1 \mathrm{~cm}$ thick. The apical zone was enucleated with the tip of the resectoscope. Then the tip of the resectoscope was inserted at the 5 or 7 o'clock position into the previous circular incision line of the urethra under direct vision. The resectoscope tip was advanced along the false capsule. Care was taken not to enter into the adenoma. Then the enucleation of the apical zone was extended from the 2 to 10 o'clock positions as widely as possible. The enucleation was halted at the bladder neck to avoid perforation. Resection of the adenoma along the surgical capsule was done longitudinally along the surgical capsule at 4 , 6 , or 8 o'clock position. Then the isolated adenoma at the lower side was resected and finally the adenoma was resected anteriorly as far as the anterior fibromuscular stroma.

For TURP same instrument was used. For resection purpose, monopolar diathermy was used using glycine water irrigation. The operative time was calculated from starting the resection up to the introduction of catheter at the end of the procedure.

Group A (30), who underwent TURP was designated as control group and Group B (30) who underwent TUERP was designated as experimental group. TURP and TUERP were performed by multiple surgeons. TURP was performed by conventional method. On $3^{\text {rd }}$ postoperative day, urethral catheter was removed in both the groups. A postoperative $\mathrm{Hb} \%$, serum electrolyte and haematocrit were performed. All patients were followed up with IPSS, QOL, Qmax, PVR and residual prostate volume at 3 months after operation.

After meticulous checking and rechecking data were compiled and statistical analysis, measures of dispersion (mean, SD) and the test of significance (t-test, Z- test and $\chi^{2}$ test) were done using computer based on statistical software (SPSS, version 13). A 'p' value $<0.05$ was considered as significant.

\section{Results}

Total patients were 60,30 in control group and 30 in experimental group. Mean age in control and experimental groups were $68.0 \pm 7.3$ and $68.7 \pm 8.2$ years respectively. Comparison of different parameters of interest are presented in table I. 
Table I. Pre and post-operative comparison of the outcome variables

\begin{tabular}{|c|c|c|c|c|c|c|}
\hline & \multicolumn{3}{|c|}{ TURP } & \multicolumn{3}{|c|}{ TUERP } \\
\hline & pre & post & $\mathrm{p}$ value & pre & post & $\mathrm{p}$ value \\
\hline IPSS & $23.4 \pm 2.2$ & $5.53 \pm 2.28$ & $<0.001$ & $23 \pm 2.3$ & $6.37 \pm 1.97$ & 0.001 \\
\hline QOL & $4.5 \pm 1$ & $1.97 \pm 0.99$ & 0.05 & $4.6 \pm 1.1$ & $1.63 \pm 1.02$ & $<0.05$ \\
\hline $\mathrm{Qmax}(\mathrm{ml} / \mathrm{sec})$ & $6.3 \pm 1.98$ & $22 \pm 6.43$ & $<0.001$ & $6.5 \pm 1.98$ & $21.7 \pm 6.98$ & $<0.01$ \\
\hline PVR & $120 \pm 8.5$ & $22.33 \pm 7.16$ & $<0.001$ & $125 \pm 7.6$ & $23.67 \pm 6.68$ & $<0.001$ \\
\hline Prostatic wt (gm) & $45.2 \pm 4.6$ & $23 \pm 2.46$ & $<0.001$ & $45 \pm 4.3$ & $12.2 \pm 1.80$ & $<0.001$ \\
\hline $\mathrm{Hb} \%$ & $15.1 \pm 0.5$ & $13.04 \pm 6.06$ & $<0.05$ & $15.2 \pm 0.5$ & $15.20 \pm 0.48$ & $>0.05$ \\
\hline $\mathrm{Na}$ & $140 \pm 4.1$ & $126 \pm 6.8$ & $<0.01$ & $136 \pm 4$ & $136 \pm 2.70$ & $>0.05$ \\
\hline
\end{tabular}

There was significant changes in IPSS, QOL, Qmax, PVR, prostate weight between pre and post-operative period in both groups and also significant fall of $\mathrm{Hg}$ and $\mathrm{Na}^{+}$in control group (Table I).

The mean operation time (for moderate prostate volume i.e. 40 to $50 \mathrm{gm}$ prostate) of Group A and Group B were 61 minutes $(\mathrm{SD} \pm 5.29)$ and 50 minutes $(\mathrm{SD} \pm 4.50)$ respectively. There was significant difference between the two groups indicating efficacy of TUERP in consuming less time for operation than TURP (P $<0.001)$.

During the intraoperative period, in TURP group $10(33.3 \%)$ patients and in TUERP group 1 patient (3.33\%) had hemorrhage necessitating blood transfusion. Seven $(23.33 \%)$ patients in TURP had hyponatremia (due to TUR syndrome) needed sodium supplementation, but no patient in TUERP procedure had hyponatremia. Postoperatively in TURP group 3 $(10 \%)$ patients had clot retention but in TUERP no patients had clot retention. In the post-discharge period urethral stricture occurred in $3(10 \%)$ patients in TURP group and in $1(3.33 \%)$ patient in TUERP group. Bladder neck contracture occurred in $3(10 \%)$ patients in TURP and $2(6.67 \%)$ in TUERP group. UTI occurred in $2(6.67 \%)$ patients in each group.

\section{Discussion}

Gunnar $\mathrm{M}$ et al. found that the average age of patient with $\mathrm{BPH}$ was 68.9 years which is consistent with those in other studies, all of which had mostly patients who were around 70 years of age. ${ }^{9}$ In our study, the average age in the Group A was $68.0(\mathrm{SD} \pm 7.3)$ and in the Group B was $68.7(\mathrm{SD} \pm 8.2)$ years which is also consistent with the other studies.
In our study all the patients indicated for surgical treatment were assessed for IPSS preoperatively. In Group A patients had IPSS 23.4 and in Group BIPSS were 23 indicating that both the groups had severe prostatism. Gunnar $\mathrm{M}$ et al. showed in their study that the mean American Urological Association (AUA) symptom score fell from 21 to 6 at 3 and 6 months and to 5 one year after TURP. ${ }^{9}$ In our study in Group A, the IPSS fell from 23.4 to 5.53 ( $\mathrm{SD} \pm 2.28$ ) and in Group B fell from 23 to $6.37(\mathrm{SD} \pm 1.97)$ after 3 months. There was no significant difference between the groups indicating same efficacy of reducing IPSS in both TURP and TUERP.

Singh $\mathrm{H}$ et al. showed significant improvement of Q max by 3 months. ${ }^{10}$ In our study the mean preoperative Qmax of Group A and Group B were $6.3 \mathrm{ml} / \mathrm{sec}$ and 6.5 $\mathrm{ml} / \mathrm{sec}$ respectively, indicating homogenous distribution of values among both the groups. The mean postoperative Qmax at 3 months of Group A was $22 \mathrm{ml} /$ $\sec (\mathrm{SD} \pm 6.43)$ and Group B was $21.7 \mathrm{ml} / \mathrm{sec}(\mathrm{SD} \pm$ 6.98) which is nearly consistent with that of Singh $\mathrm{H}$ et al. There were no significant difference between the two groups regarding the postoperative $\mathrm{Qmax}(\mathrm{P}>0.1)$ indicating that in regard to $\mathrm{Qmax}$ both the procedures are efficient in same fashion.

Shimizu Y et al. showed TURP leaves a lot of residual adenoma and has a high recurrence rate. Total adenoma resection was performed via standard TURP in 64 cases with BPH and the weight of the residual adenoma was measured by transurethral enucleation (TUE) of the prostate. After TURP residual adenoma was confirmed in all cases by TUE, and the average weight of the 
residual adenoma was $10.2 \mathrm{gm}$. The total average prostate volume removed by TURP and TUE was 20.1 $\mathrm{gm}$. The average residual rate of the adenoma removed by TURP was $54.5 \%$. TURP leaves about half of the adenoma. They concluded TURP might be very difficult for complete resection of an adenoma. They tried a complete detachment of the whole prostate lobes for BPH by transurethral enucleation of the prostate (TUE). For $46 \mathrm{BPH}$ cases the whole prostate lobes were detached from the surgical capsule completely by a prostate-detaching blade and resectoscope beak, and dropped into the bladder. The detached prostate lobes were removed by a soft tissue morcellator. The preoperative total prostate and adenoma volume by transabdominal ultrasound measurement were $47.75 \pm$ 25.63 and $27.8 \pm 17.33 \mathrm{ml}$. In all $46 \mathrm{BPH}$ cases, the whole prostate lobes could be detached completely without a perforation. The mean of removed tissue weight was $37.11 \mathrm{~g}, 1.65 \mathrm{mg} / \mathrm{dl}$. They concluded Transurethral detachment of prostate (TUDP) could achieve complete removal of a large adenoma. ${ }^{11}$ In our study the mean preoperative prostatic weight determined by TRUS of Group A and Group B were 45.2 gm and $45 \mathrm{gm}$ respectively. The mean postoperative prostate weight at 3 months of Group A and Group B were 23 $\mathrm{gm}(\mathrm{SD} \pm 2.46)$ and $12.2 \mathrm{gm}(\mathrm{SD} \pm 1.80)$ respectively. There was significant difference between the two groups indicating efficacy of TUERP in removing more tissue than TURP $(\mathrm{P}<0.001)$ indicating the efficacy of TUERP over TURP in removing prostatic tissue.

Kuo RL et al showed the decrease in hemoglobin after surgery is greatest with open prostatectomy, followed by that with TURP and least with TUERP and HoLEP. In their study the range of $\mathrm{Hb}$ decrease was 0.3 to 3.83; $($ Mean $=1.73, \mathrm{SD}=0.83) .{ }^{12}$ In our study the mean preoperative $\mathrm{Hb} \%$ level of Group A and Group B were $15.1 \mathrm{gm} / \mathrm{dl} \mathrm{gm}$ and $15.5 \mathrm{gm} / \mathrm{dl}$ respectively. The mean perioperative (immediate postoperative, i.e. within 24 hours) $\mathrm{Hb} \%$ level of Group A and Group B were 13.04 $\mathrm{gm} / \mathrm{dl} \mathrm{gm}(\mathrm{SD} \pm 6.06)$ and $15.20 \mathrm{gm} / \mathrm{dl}(\mathrm{SD} \pm 0.48)$ respectively. There was significant difference between the two groups indicating efficacy of TUERP in reducing $\mathrm{Hb} \%$ drop than TURP $(\mathrm{P}<0.05)$.

Berg et al showed a significant relationship between the postoperative drop in serum sodium concentration and total volumetric gain, including IV fluids, was also observed $(\mathrm{P}=0001)$. The results of this study showed that the mean drop in serum $\mathrm{Na}^{+}$was significant in symptomatic but not overall cases. The changes in serum sodium and glycine were significant in both symptomatic and asymptomatic cases. ${ }^{13}$ In our study the mean preoperative $\mathrm{Na}^{+}$level of Group A and Group B were $140 \mathrm{mmol} / \mathrm{l}$ and $142 \mathrm{mmol} / \mathrm{l}$ respectively. The mean perioperative (immediate postoperative) $\mathrm{Na}^{+}$level of Group A and Group B were $126 \mathrm{mmol} / \mathrm{l}(\mathrm{SD} \pm 6.8)$ and $136 \mathrm{mmol} / 1(\mathrm{SD} \pm 2.70)$ respectively. There was significant difference between the two groups indicating efficacy of TUERP in reducing $\mathrm{Na}^{+}$drop than TURP (P $<0.001)$.

\section{Conclusion}

TUERP allows complete resection down to the surgical capsule, and BPH can be removed more easily and safely than by conventional TURP. A multi-center comparative study may be done in Bangladesh for further recommendations.

\section{Conflict of interest: None}

\section{References}

1. Berry SJ, Coffey DS, Walsh PC. The development of human prostatic hyperplasia with age. J Urol 1984;132(11):474-79.

2. Arrighi HM, Meffer FJ, Guess HA, Fozzard JI. Natural history of Benign Prostatic Hyperplasia and Risk of Prostatectomy. Urology 1991;38(12):4-8.

3. Mebust WK, Holtgrewe HL, Cockett AT, Peters PC. Transurethral prostatectomy: Immediate and postoperative cimolications: A cooperative study of 13 participating institutions evaluating 3,885 patients. J Urol 1989;141: 243-47.

4. Holtgrewe HL, Valk WL. Factors influencing the mortality and morbidity of transurethral prostatectomy: A study of 2,015 cases. J Urol 1962;87(3):450-59.

5. Hammadeh MY, Fowlis GA, Singh M, Philp T. Transurethral electrovaporization of the prostate: a possible alternative to transurethral resection: A one-year follow-up of a prospective randomized trial. British J Urol 1998;81(12): 721-25.

5. Borboroglu PG, Kane CJ, Ward JF, Roberts JL, Sands JP. Immediate and postoperative complications of transurethral prostatectomy in the 1990s. J Urol 1999;162(12):1307-10.

6. Schatzl G, Madersbacher S, Djavan B, Lang T, Marberger M. Two year results of transurethral resection of the prostate versus four "less-invasive" treatment options. Eur Urol 2000;37;695-701. 
7. Thalmann GN, Mattei A, Treuthardt C, Burkhard FC, Studer UE. Transurethral microwave therapy in 200 patients with minimum follow up of 2 years: Urodynamic and clinical results. J Urol 2002;16(12):2496-2501.

8. Zlotta AR, Giannakopoulos X, Maehlum O, Ostrem T, Schulman CC. Long term evaluation of transurethral needle ablation of the prostate (TUNA) for treatment of symptomatic benign prostatic hyperplasia: Clinical outcome up to 5 years from 3 centers. Eur Urol 2003;44(13):89-93.

9. Gunnar M, Holtgrewe HL, Cockett AT, Peters PC. Transurethral prostatectomy: Mortality and morbidity. Prostate 1996;28(11):195-200.
10. Singh H, Moody J, Lingeman J. Holmium laser enucleation of the prostate with tissue morcellation : initial United States experience. J Endourol 2000;14(12):219-21.

11. Shimizu Y, Hiraoka Y, Iwamoto K, Takahashi H, Abe H. Measurement of residual adenoma after transurethral resection of prostate by transurethral enucleation technique. Urol Int 2005;74(12):102-107.

12. Kuo RL, Kim SC, Lingeman JE, Paterson RF, Watkins SL, Simmons GR. Holmium laser enucleation of prostate (HoLEP): the Methodist Hospital experience with greater than 75 gram enucleations. J Urol 2003;170(1):149-52.

13. Berg G, Fedor EJ, Fisher B. Physiologic observations related to the trnsurethral resection reaction. J Urol 1962: 087: 596600 . 